\title{
Effects of microhabitat on rodent-mediated seed removal of endangered Kmeria septentrionalis in the karst habitat
}

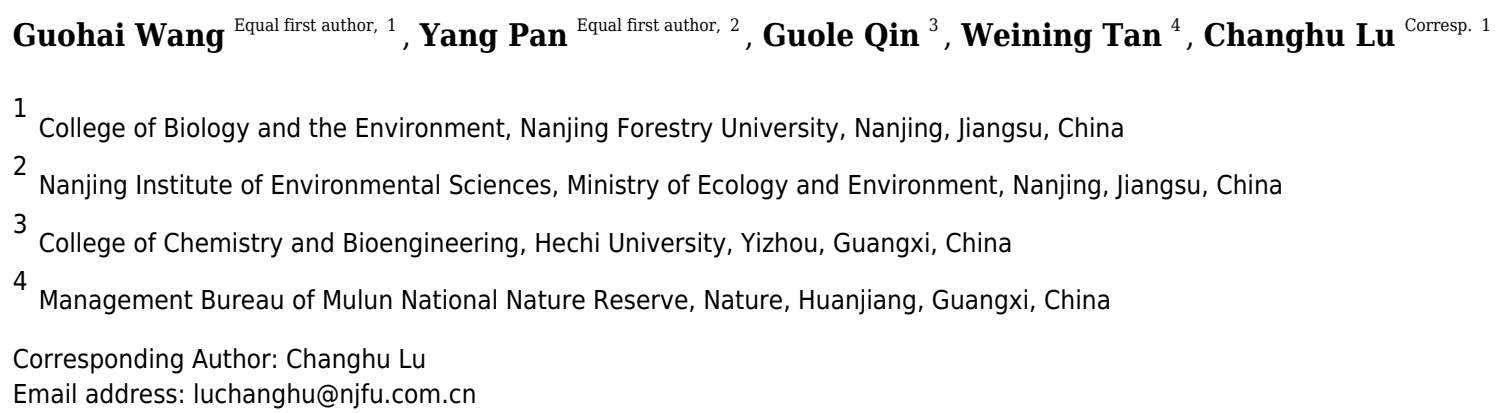

Seed removal behaviors of rodents are largely influenced by microhabitat. Although the karst ecosystem is composed of a broad variety of microhabitats, we have no information on how they affect such behaviors. We investigated rodents' seed removal behaviors in four karst microhabitats (stone cavern, stone groove, stone surface, and soil surface) using three types of Kmeria septentrionalis seeds: fresh, black (intact seeds with black aril that dehydrates and darkens), and exposed (clean seeds without the aril). We show that Rattus norvegicus, Leopoldamys edwardsi and Rattus flavipectus were the predominant seed predators. Even though all seed types experienced a high removal rate in all four microhabitats, but rodents preferentially removed seeds from the three stone microhabitats (stone caves: $69.71 \pm 2.74 \%$; stone surface: $60.53 \pm 2.90 \%$; stone groove: $56.94 \pm 2.91 \%)$ compared to the soil surface (53.90 $\pm 2.92 \%)$. Seeds that had been altered by being exposed to the environment were more attractive to rodents than fresh seeds (76.25 $\pm 2.20 \%$ versus $36.18 \pm 2.29 \%$ ). The seed removal behavior of rodents was significantly affected by the microhabitat and seed type. Finally, seeds that had fallen on the soil surface microhabitat incurred a lower predation risk than seeds fallen on other microhabitats, which increased their probability to germinate. Our results indicate that the lower predation rate of seeds from the endangered $K$. septentrionalis dropped on the soil surface increases trees' likelihood of survival. 
1 Effects of microhabitat on rodent-mediated seed removal of endangered Kmeria

2 septentrionalis in the karst habitat

3

7 National Nature Reserve, Huanjiang, Guangxi, China.

8 Corresponding author

9 Changhu Lu, luchanghu@njfu.com.cn

\section{ABSTRACT} likelihood of survival.

Seed removal behaviors of rodents are largely influenced by microhabitat. Although the karst ecosystem is composed of a broad variety of microhabitats, we have no information on how they affect such behaviors. We investigated rodents' seed removal behaviors in four karst microhabitats (stone cavern, stone groove, stone surface, and soil surface) using three types of Kmeria septentrionalis seeds: fresh, black (intact seeds with black aril that dehydrates and darkens), and exposed (clean seeds without the aril). We show that Rattus norvegicus, Leopoldamys edwardsi and Rattus flavipectus were the predominant seed predators. Even though all seed types experienced a high removal rate in all four microhabitats, but rodents preferentially removed seeds from the three stone microhabitats (stone caves: $69.71 \pm 2.74 \%$; stone surface: $60.53 \pm 2.90 \%$; stone groove: $56.94 \pm 2.91 \%)$ compared to the soil surface $(53.90 \pm 2.92 \%)$. Seeds that had been altered by being exposed to the environment were more attractive to rodents than fresh seeds $(76.25 \pm 2.20 \%$ versus $36.18 \pm$ $2.29 \%$ ). The seed removal behavior of rodents was significantly affected by the microhabitat and seed type. Finally, seeds that had fallen on the soil surface microhabitat incurred a lower predation risk than seeds fallen on other microhabitats, which increased their probability to germinate. Our results indicate that the lower predation rate of seeds from the endangered $K$. septentrionalis dropped on the soil surface increases trees'

Keywords: Kmeria septentrionalis; Seed removal; Microhabitat; Seed type; Karst habitat

\# These authors contributed equally to this paper. 
27

28

\section{INTRODUCTION}

Seed removal by rodents is one of the most important dispersal mechanisms for many plant species (Lichti et al., 2017; Wang \& Corlett, 2017). They tend to transport seeds away from the mother tree, where they would otherwise experience strong parental competition (Nathan \& Muller-Landau, 2000; Jansen et al., 2014). This behavior also increases the chances of seeds reaching a suitable germination habitat and facilitates their distribution (Steele et al., 2015; Wang \& Corlett, 2017). The pattern and intensity of seed removal depends on a multitude of biotic and abiotic factors, such as seed traits and availability (Dylewski et al., 2020; Xiao et al., 2015), rodent abundance ( $\mathrm{Li} \&$ Zhang, 2007) and habitat characteristics (Wang et al., 2019b; Perea et al., 2012). A seed's microhabitat is one of the most important factors affecting its removal (García-Castaño et al., 2006; Steele et al., 2015).

Microhabitats provide a variety of biological and abiotic conditions for the survival of rodents (Vander-wall, 2000; Fleury \& Galetti, 2006) and determine the quality of the foraging habitat through predation risk and foraging costs. A microhabitat's characteristics influence the abundance, activity intensity, and spatial distribution of rodents (Pérez-Ramos \& Marañón, 2008), ultimately affecting the probability of seed encounters and foraging behaviors of seed predators (e.g., removal or in situ consumption; Perea et al., 2012; Reed et al., 2005). For example, Peromyscus polionotus removed more seeds from dense vegetation cover than from open patches where there was a higher possibility of being confronted by predators (Orrock et al., 2004). The foraging behavior of rodents with respect to seeds in different microhabitats affects seedling regeneration, spatial distribution, and the diversity of trees (Hirsch et al., 2012; Zhang et al., 2016). Steele et al. (2014) found that eastern gray squirrels (Sciurus carolinensis) dispersed larger, more profitable acorns (Quercus spp.) into open habitats, with a lower rate of cache pilferage, and better conditions for seedling establishment. The seed removal behavior of rodents is also affected by changes in seed presentation (cleaned seeds versus seeds within the pulp) (Perea et al., 2011; Pan et al., 2016). Some studies have shown that rodents prefer to remove exposed seeds that have been regurgitated or defecated by birds versus intact seeds (Perea et al., 2011).

The karst habitat of southwest China represents one of the world's most spectacular examples of tropicalsubtropical karst landscapes. It is characterized by high edaphic and topographic heterogeneity formed by several types of microhabitats (e.g. stone groove, stone crevice, and stone cavern) (Clements et al., 2006; 
55 Zhang et al., 2013). The plants in the karst habitat bear a large amount of seeds every year (Pan et al., 2008;

56 Tang et al., 2011), but it is extremely difficult for them to spread over long distances due to geographic

57 barriers and most of them end up randomly falling into various microhabitats around the mother tree.

58 Therefore, the seeds of many plants in the karst habitat must rely on ground-dwelling rodent removal to a

59 suitable microhabitat for germination. However, there are few studies on the behavior of rodent seed predators

60 in the karst habitat.

61 Kmeria septentrionalis is a dioecious tree species of the Magnoliaceae with a red aril that is endemic to 62 China and is listed as an endangered species by the IUCN. It is a first-class national protected plant in China 63 (Lin et al., 2011). The seeds rely on birds for their dispersal and become completely exposed after passing 64 through bird's digestive system, which results in them having no pulp (Wang et al., 2019a). Seeds that are not 65 removed by birds fall to the ground and remain intact (fresh seeds) and the red aril of fresh seeds dehydrates 66 and turns black (black seeds) after approximately $138.20 \pm 3.86 \mathrm{~h}(\mathrm{n}=30)$. The topographic heterogeneity of 67 karst habitat forms several types of microhabitats (e.g., stone groove, stone crevice, and stone cavern) 68 (Clements et al., 2006; Zhang et al., 2013) and the three types of K. septentrionalis seeds (fresh seeds, black 69 seeds, and exposed seeds) are often randomly distributed in different microhabitats under the mother trees.

70 We conducted a rodent-mediated seed removal experiment in four karst microhabitats (stone cavern, stone groove, stone surface, and soil surface) with three types of $K$. septentrionalis seeds (fresh seeds, black seeds, and exposed seeds) to determine the effect of the microhabitat on the seed removal behavior of rodents. We had two objectives: (1) how karst microhabitats affect seed removal behaviors from rodents predating on seeds of K. septentrionalis; (2) to determine whether rodents preferred a specific seed type. We predicted that the seed removal rate in the stone microhabitats was higher than in the soil surface, and fresh seeds had lower removal rate than other types.

\section{MATERIALS \& METHODS}

\section{Ethics statement}

Field studies were conducted under the permission from the Administrative Bureau of Mulun National Nature 


\section{Study area}

83 We performed field experiments in the Mulun National Nature Reserve $\left(107^{\circ} 54^{\prime} 01^{\prime \prime}-108^{\circ} 05^{\prime} 51^{\prime \prime} \mathrm{E} ; 2^{\circ} 07^{\prime} 01^{\prime \prime}-\right.$ $8425^{\circ} 12^{\prime} 22^{\prime \prime} \mathrm{N}$ ) in Guangxi Zhuang Autonomous Region, southwest of China (Fig.1). The nature reserve has 85 typical karst landforms consisting of peak-cluster depressions and valleys, and altitudes ranging from 300$1000 \mathrm{~m}$ above sea level. The climate in this region is dominated by the mid-subtropical zonal monsoon and the averages annual air temperature is approximately $19.3^{\circ} \mathrm{C}$, ranging from $-5^{\circ} \mathrm{C}$ in January to $26.7^{\circ} \mathrm{C}$ in July. The annual rainfall averages $920 \mathrm{~mm}$ with the highest amounts of rainfall occurring from June to September (Liu et al., 2012). The annual frost-free period lasts approximately 235-290 days, and the relative humidity is typically higher than 79\% (Pan et al., 2008). The local vegetation dominated by middle subtropical evergreen and deciduous broad-leaved mixed forest, including species liked K. septentrionalis, Lindera communis, Machilus pingii, and Loropetalum chinense (Wang et al., 2019a).

\section{$93 \quad$ Study species}

Kmeria septentrionalis is classified as an endangered species by the IUCN (Lin et al., 2011) and is only found in the karst habitat of the Guangxi Zhuang Autonomous Region (Luocheng, Huanjiang), Guizhou Province (Libo) and Yunnan Province (Malipo, Maguan). Most plants are found in the Mulun National Nature Reserve (Pan et al., 2008). Female plants bear 100-300 fruits annually and each fruit contains 4-14 seeds (mean \pm standard error, length, $1.14 \pm 0.15 \mathrm{~cm}$; width, $0.49 \pm 0.06 \mathrm{~cm}$ and weight, $0.23 \pm 0.03 \mathrm{~g} ; \mathrm{n}=30)($ Wang et al., 2019a). The fleshy arils turn red in autumn and attract birds to forage and disperse the seeds. Hemixos castanonotus, Yuhina castaniceps, and Pericrocotus flammeus are the main seed dispersers, and these birds consume large numbers of seeds, which are excreted to various microhabitats after passing through the birds' digestive tracts (Wang et al., 2019a).

Fig.1 Location map of Mulun National Nature Reserve, China.

\section{Rodent species survey}

We baited live traps $(25 \mathrm{~cm} \times 11 \mathrm{~cm} \times 11 \mathrm{~cm}$; Power of Arrest, China) with peanuts and fresh K. septentrionalis seeds to determine the species of rodents under the canopies of the mother forest during the mature period of $K$. septentrionalis seeds. The trapping stations were set approximately $5 \mathrm{~m}$ apart to minimize the effects of trapping in microhabitats where the seeds were placed. Three $30 \mathrm{~m}$ transects were selected according to the 
109

110

111

112

113

114

115

116

117

118

distribution of the mother trees, and 5 trap stations were set at $5 \mathrm{~m}$ intervals each transect for ten consecutive days. 150 traps were set in total. Traps were left open and were checked daily at 7:00 am and 7:00 pm. We recorded the species and body weights of the captured rodents, which were released immediately after feeding on different types of K. septentrionalis seeds. Six infrared cameras (Loreda L710, Leyueda Electronics Co., Ltd. Shenzhen, China) were set at $10 \mathrm{~m}$ intervals to monitoring the rodent species. The cameras were set to take three photos and one video after each trigger. The time interval between each trigger was $5 \mathrm{~s}$. All cameras were operated for $24 \mathrm{~h}$ a day over ten consecutive days.

\section{Selection of microhabitats for seed placement}

Stone cavern, stone groove, stone surface, and soil surface were the most representative karst microhabitats found in the study area. The microhabitats were distributed under the tree canopies of $K$. septentrionalis trees. We selected these four karst microhabitats as seed placement sites to study the seed removal rates of $K$. septentrionalis seeds. The specific definitions of these microhabitats are description by Lu et al. (2010) (Table 1, Fig. 2).

Table1 Description of karst microhabitats in the study area.

Fig. 2 Photograph of four karst microhabitats in the study area.

\section{Seed removal experiment}

Seed removal experiments were conducted in late September to mid-October 2018 during the natural maturity season of $K$. septentrionalis seeds. Three types of $K$. septentrionalis seeds were placed in the four microhabitats. Seeds with intact fleshy arils that untouched by animals were referred to as 'fresh seeds', and were collected from the ground or directly from different mother trees. Black seeds, referred to as 'intact seeds', had a black aril that had not been touched by animals. These were collected from the ground or created by placing intact fresh seeds on the ground for approximately $138.20 \pm 3.86 \mathrm{~h}(\mathrm{n}=30)$. Exposed seeds, referred to as 'clean seeds', after passed through the digestive tract of birds and had no aril or pulp. It was difficult to collect a statistically significant number of exposed seeds on the ground because of the high heterogeneity of the karst habitat so we created clean seeds by carefully extracting them from the fresh seeds. We wore plastic gloves when collecting the $K$. septentrionalis seeds and preparing the experimental apparatus to avoid contamination.

Three types of seeds were placed in each microhabitat in three plastic Petri dishes (diameter, $90 \mathrm{~mm}$ ), which 
were placed at intervals of at least $10 \mathrm{~cm}$. Thirty seeds of each type were placed in each Petri dish (30 fresh seeds, 30 black seeds, 30 exposed seeds). 90 seeds in total were placed in each microhabitat. We set up seven stations for each microhabitat every day, totaling twenty-eight stations, with an interval of $10 \mathrm{~m}$ between two stations to ensure the independence of experimental units. We dismantled and re-established all the stations randomly every day to avoid any spatial pseudoreplication and the experiments were carried out over 10 consecutive days. Our experimental set-up consisted of 280 microhabitat stations, 840 plastic Petri dishes, and 25200 seeds $(30 \times 3 \times 28 \times 10)$. Seeds were placed on Petri dishes in the morning and left for $24 \mathrm{~h}$. The state of the seeds and data were checked and recorded daily at (0700-0900 h). The remaining seeds were removed and replaced with new ones. During the field observations, it was noted that ants do not remove the seeds of $K$. septentrionalis, but they fed on the elaiosome of seeds in situ. We were able to confirm that the seeds of $K$. septentrionalis were consumed or removed by rodents based on trapping, infrared camera monitoring, and subsequent feeding trials in cages. We did not record the final state of the seeds but we considered the seeds removed by rodents if they (i) were missing from the plastic Petri dishes; or (ii) were still on the dishes but were gnawed and empty (García et al., 2007; Pan et al., 2016). The removal rate was calculated as the proportion of removed seeds relative to the initial number of seeds, and the average removal rate was taken as the removal rate for each microhabitat and seed type.

\section{Statistical analysis}

Mann-Whitney $U$ tests were used to compare the differences in seed removal rates between the two microhabitats and seed types, respectively. Generalized linear mixed models (GLMM; lme4 package, version 3.2.5, $R$ Core Team, 2016) were used to estimate the effect of microhabitats and seed types on the seed removal rate with the day of the experiment and the microhabitat station ID set as random factors. All data analysis and figure creation were performed using the R program, and the level of statistical significance was set at $P<0.05$.

\section{RESULTS}

\section{Rodent species}

9 rodents were trapped, and the trap success was estimated at $6.00 \%$, representing a low level of rodent abundance. Rattus norvegicus made up 55.56\% (n=5), Leopoldamys edwardsi made up $33.33 \%(\mathrm{n}=3)$, and $R$. flavipectus made up $11.11 \%(\mathrm{n}=1)$ of the total number of rats trapped. A total of 548 photos and 174 videos 
165

166

167

168

were taken by the infrared camera, of which 362 pictures and 69 videos contained rodents. All of the rodents captured on camera were unique members of the three types of rodents. The seed traces were the same in the captured rodents as those in the field, and infrared cameras recorded videos showing these rodents were the main predators of $K$. septentrionalis seeds.

\section{Seed removal}

There was a relatively high rate of seed removal in all of the microhabitats. The average seed removal rate in three of the stone microhabitats was perceptibly higher than that of the soil surface microhabitat $53.90 \pm 2.92 \%$ (stone cavern: $69.71 \pm 2.74 \%$; stone surface: $60.53 \pm 2.90 \%$; and stone groove: $56.94 \pm 2.91 \%$ ). Significant differences were noted in the seed removal rate between the stone cavern and other microhabitats $(\mathrm{P}<0.001)$, respectively (Fig.3).

Exposed seeds had the highest average removal rate across all microhabitats (69.8\%-84.1\%), and fresh seeds had the lowest removal rate (30.8\%-46.2\%) (Fig.3). The removal rates of fresh seeds were significantly different from those of black seeds and exposed seeds in all microhabitats $(\mathrm{P}<0.001)$. The removal rates of black seeds and exposed seeds were only significantly different in the stone groove microhabitat ( $\mathrm{P}=0.013)$. Furthermore, the seed removal rate was significantly affected by both microhabitat and seed type (Table 2). The seeds placed in stones caves and the exposed seeds seemed to attract rodents because they had the highest removal rates.

Fig.3 The seed removal rates in different microhabitats and seed types.

Table 2 Results of generalized linear mixed models (GLMM) evaluating the effects of microhabitats and seed types on the removal rate of $K$. septentrionalis seeds.

\section{DISCUSSION}

We found that all types of seeds in the four microhabitats had a high removal rate by rodents (Fig.3), which is similar to other studies that also reported such high rate of seed removal by rodents (Vander-Wall, 2003; Pan et al., 2016; Li \& Zhang, 2007). Only nine rodents were captured, representing a low level of rodent abundance, which may be due to the close proximity of the study area to a village. A large number of Ipomoea batatas, Oryza sativa and Glycine max were planted in nearby farmlands during the mature period of the $K$. septentrionalis seed. The small size and low nutrient content of $K$. septentrionalis seed encourages the migration of rodents to nearby farmland to obtain enough food to meet their daily energy needs, reducing the 
193

194

density of the rodent population in the forest. Previous studies have shown that L. edwardsi, R. norvegicus, and R. flavipectus tend to cache seeds for later use in periods of food scarcity (Chang et al., 2010; Shepherd \& Ditgen, 2013; Cao et al., 2018). Rodents prefer to disperse and cache large seeds with high nutritional value and will consume small seeds immediately to compensate for energy expenditure during foraging (Chang et al., 2009; Cao et al., 2018). The medium size of K. septentrionalis seeds have a lower nutrient content (Zheng, 2016), and the rodents needed to consume more seeds to ensure sufficient nutrition. Many seed fragments were left around the Petri dishes, leading us to speculate that most of these seeds were probably eaten in situ by rodents and not removed and cached. Similar results have been found in other studies of fleshy fruits (Garcia et al., 2005; Pan et al., 2016). It has been suggested that the seed fragments discarded by rodents may germinate and develop seedlings (Loayza et al., 2014), however, when we followed up after a year there were no successfully germinated of the seed fragments discarded by rodents, indicating that rodents may be predators to the seeds of $K$. septentrionalis.

The seed removal rates in stone microhabitats were significantly higher than those on the soil surface (Fig.3). This pattern could be attributed to the foraging behavior of small rodents, which are more active in sheltered microhabitats (Pérez-Ramos \& Marañón, 2008). Stone microhabitats may provide a refuge for rodents, reducing their exposure time, and the risk of being caught by predators. This was especially true in the stone cavern where the risk of being caught by large carnivorous predators was reduced because of the complex and narrow space, and darkened conditions are more conducive to rodent hiding (Vander-Wall, 2000). However, the high seed removal rates in stone microhabitats may not facilitate regeneration for this endangered plant species. This is not only because habitat conditions, such as shallow soils, and low nutrient and water contents, do not create a conducive environment for K. septentrionalis seed germination and seedling growth, but also because the rodents that were fed $K$. septentrionalis seeds in situ do not leave any behind to germinate. Conversely, seeds fallen on the soil surface incurred a lower predation risk, and we found that almost all the seedlings were grown in the soil surface when investigated the establishment of $K$. septentrionalis populations

in fields (Supplemental File 1). Therefore, we deduced that the seeds that fallen on the soil surface microhabitat may survive and that the soil surface might be more beneficial to the establishment of plants than other karst microhabitats. 
220

221

222

The probability of seeds being removed varied by the type of seed, and fresh seeds had the lowest removal rate in all microhabitats (Fig.3), which supports the findings of other studies (Perea et al., 2011; Pan et al., 2016). The intra-specific differences in seed removal rates may be related to secondary metabolites in these seeds. Fresh seeds of $K$. septentrionalis contained large amounts of volatile monoterpenoids and possibly had poor palatability (Huang et al., 2010), which may reduce the interest in seed removal by rodents. However, the seeds become dehydrated and turn black after falling to the ground, and it is possible that the concentration of some of the unpalatable secondary substances may decrease during this process, increasing the rate of seed removal. Additional studies should focus on the secondary substances involved their influence on the removal of $K$. septentrionalis seeds by rodents. We found that rodents always use fruit-handling methods and bit into the aril to feed on the seed kernel, rather than removing or consuming the whole seed. Exposed seeds, which are easier for rodents to manipulate than intact seeds, were favored, reflecting a foraging behavior that involves acquiring the most energy with the least input of time and energy and the lowest predation risk (Fedriani \& Manzaneda, 2005). Exposed seeds had the highest removal rate across all microhabitats (Fig.3). Other studies also found that the removal rate of exposed seeds was greater than that of intact seeds (Perea et al., 2011).

\section{CONCLUSIONS}

Our study suggested that the seed removal rate by rodents was significantly affected by the various karst microhabitats and the seed types of $K$. septentrionalis. The seed removal rates in stone microhabitats were significantly higher than on the soil surface microhabitat. Rodents preferred to remove seeds in stone caves and exhibited a preference for exposed seeds. Therefore, we determined that the seeds dropped on the soil surface face a lower predation rate and will increase the survival of the endangered $K$. septentrionalis.

\section{ACKNOWLEDGMENTS}

We thank the staff of the Mulun National Nature Reserve for their contributions in the field.

\section{ADDITIONAL INFORMATION AND DECLARATIONS}

\section{Funding}

This study was supported by the National Natural Science Foundation of China (No.30970470) and Jiangsu Planned Projects for Postdoctoral Research Funds (No. 2018K064B). The funders had no role in study design, data collection and analysis, decision to publish, or preparation of the manuscript. 


\section{Grant Disclosures}

248 The following grant information was disclosed by the authors:

249 National Natural Science Foundation: 30970470.

250 Jiangsu Planned Projects for Postdoctoral Research Funds: 2018K064B.

251 Competing Interests

252 The authors declare there are no competing interests.

\section{Author Contributions}

254 Guohai Wang conceived and designed the experiments, analyzed the data, prepared figures and/or tables, 255 authored or reviewed drafts of the paper, approved the final draft.

256 - Yang Pan conceived and designed the experiments, analyzed the data, prepared figures and/or tables, 257 authored or reviewed drafts of the paper, approved the final draft.

$258 \cdot$ Guole QIN analyzed the data, prepared figures and/or tables.

$259 \cdot$ Weining Tan contributed reagents/materials/analysis tools.

260 Changhu Lu conceived and designed the experiments, contributed reagents/materials/-analysis tools, authored 261 or reviewed drafts of the paper, approved the final draft.

\section{REFERENCES}

263 Cao L, Yan C, Wang B. 2018. Differential seed mass selection on hoarding decisions among three sympatric rodents. Behavioral Ecology and Sociobiology 72(10):161. DOI 10.1007/s00 265-018-2576-5.

Chang G, Xiao ZS, Zhang ZB. 2009. Hoarding decisions by Edward's long-tailed rats (Leopoldamys edwardsi) and South China field mice (Apodemus draco): The responses to seed size and germination schedule in acorns. Behavioural Processes 82:7-11. DOI 10.1016/ j.beproc.2009.03.002.

Chang G, Xiao ZS, Zhang ZB. 2010. Effects of burrow condition and seed handling time on hoarding strategies of Edward's long-tailed rat (Leopoldamys edwardsi). Behavioural Processes 85(2):163-166. DOI 10.1016/j.beproc.2010.07.004.

Clements R, Sodhi NS, Schilthuizen M, Ng PKL. 2006. Limestone Karsts of Southeast Asia: Imperiled Arks of Biodiversity. Bioscience 56(9):733-742. DOI jstor.org/stable/10.1641.

Dylewski L, Ortega YK, Bogdziewicz M, Pearson DE. 2020. Seed size predicts global effects of small mammal seed predation on plant recruitment. Ecology Letters 23(6):1024-1033. DOI 10.1111/ele.13499. 
275

276

277

278

279

280

281

282

283

284

285

286

287

288

289

290

291

292

293

294

295

296

297

298

299

300

301

Fedriani JM, Manzaneda AJ. 2005. Fedriani J M, Manzaneda A J. Pre-and post-dispersal seed predation by rodents: balance of food and safety. Behavioral Ecology 16(6):1018-1024. DOI 10.1093/beheco/ari082.

Fleury M, Galetti M. 2006. Forest fragment size and microhabitat effects on palm seed predation. Biological Conservation 131(1):1-13. DOI 10.1016/j.biocon.2005.10. 049.

García-Castaño JL, Kollmann J, Jordano P. 2006. Spatial variation of post-dispersal seed removal by rodents in highland microhabitats of Spain and Switzerland. Seed Science Research 16(3):213-222. DOI $10.1079 /$ SSR2006245.

García D, Obeso JR, Martínez I. 2005. Rodent seed predation promotes differential recruitment among birddispersed trees in temperate secondary forests. Oecologia 144(3):435-46. DOI 10.1007/s00442-005-01037.

García D, Martínez I, Obeso JR. 2007. Seed transfer among bird-dispersed trees and its consequences for post-dispersal seed fate. Basic and Applied Ecology 8(6):533-543. DOI 10.1016/j.baae.2006.11.002.

Hirsch BT, Kays R, Pereira VE, Jansen PA. 2012. Directed seed dispersal towards areas with low conspecific tree density by a scatter-hoarding rodent. Ecology Letters 15(12):1423-1429. DOI 10.1111/ele.12000.

Huang PX, Zhou YH, Nai JY, Li WG, Liu XM. 2010. Extraction and analysis of volatile constituents from testa of rare and endangered plant Kmeria septentrionalis. Guihaia 30(5):691-695.

Jansen PA, Visser MD, Joseph WS, Rutten G, Muller-Landau HC. 2014. Negative density dependence of seed dispersal and seedling recruitment in a Neotropical palm. Ecology Letters 17(9):1111-1120. DOI 10.1111/ele.12317.

Li HJ, Zhang ZB. 2007. Effects of mast seeding and rodent abundance on seed predation and dispersal by rodents in Prunus armeniaca (Rosaceae). Forest Ecology and Management 242(2-3):511-517. DOI $10.1007 / \mathrm{s} 11258-017-0735-9$.

Lichti NI, Steele MA, Swihart RK. 2017. Seed fate and decision-making processes in scatter hoarding rodents. Biological Reviews 92(1):474-504. DOI 10.1111/brv.12240.

Lin YF, Zeng LY, Zhang QW, Wang YF, Tang SQ. 2011. Development of microsatellite markers in Kmeria septentrionalis (Magnoliaceae), an endangered Chinese tree. American Journal of Botany 98(6):e158- 
302

303

304

305

306

307

308

309

310

311

312

313

314

315

316

317

318

319

320

321

322

323

324

325

326

327

328

e160. DOI 10.3732/ajb.1100039.

Liu L, Song TQ, Peng WX, Wang KL, Du H, Lu SY, Zeng FP. 2012. Spatial heterogeneity of soil microbial biomass in Mulun National Nature Reserve in Karst area. Acta Ecologica Sinica 32(1):207-214.

Loayza AP, Carvajal DE, García-Guzmán P, Gutierrez JR, Squeo FA. 2014. Seed predation by rodents results in directed dispersal of viable seed fragments of an endangered desert shrub. Ecosphere 5(4):1-9. DOI 10.1890/ES13-00283.1.

Lu YF, Li AD, Zhang YW, Yang R, Yu LF. 2010. A study on habitats to different succession stages of degraded karst vegetation-A case study of microhabitat type at huajiang. Guizhou Science 28(3):23-28.

Nathan R, Muller-Landau HC. 2000. Spatial patterns of seed dispersal, their determinants and consequences for recruitment. Trends in Ecology and Evolution 15(7):278-285. DOI 10.1016/S0169-5347(00)01874-7.

Orrock JL, Danielson BJ, Brinkerhoff RJ. 2004. Rodent foraging is affected by indirect, but not by direct, cues of predation risk. Behavioral Ecology 15(3):433-437. DOI 10.1093/beheco/ arh031.

Pan CL, Nai JY, Li XD. 2008. Seed rain and natural regeneration of Kmeria septentrionalis in Mulun of Guangxi. Chinese Journal of Ecology 27(12):2235-2239.

Pan Y, Bai B, Xiong TS, Lu CH. 2016. Seed handling by primary frugivores differentially influence postdispersal seed removal of Chinese yew by ground-dwelling animals. Integrative Zoology 11(3):191-198. DOI 10.1111/1749-4877.12189.

Perea R, San MA, Gil L. 2011. Disentangling factors controlling fruit and seed removal by rodents in temperate forests. Seed Science Research 21(3):227-234. DOI10.1017/s09602585-11000122.

Perea R, San MA, Martínez-Jauregui M, Valbuena-Carabaña M, Gil L. 2012. Effects of seed quality and seed location on the removal of acorns and beechnuts. European Journal of Forest Research 131(3):623631. DOI 10.1007/s10342-011-0536-y.

Pérez-Ramos IM, Marañón T. 2008. Factors affecting post-dispersal seed predation in two coexisting oak species: Microhabitat, burial and exclusion of large herbivores. Forest Ecology and Management 255:3506-3514. DOI 10.1016/j.foreco.2008.02.032.

R Core Team. 2016. R: a language and environment for statistical computing. R Foundation for Statistical Computing, Vienna. Available at http://www.R-project.org/. 
329

330

331

332

333

334

335

336

337

338

339

340

341

342

Reed AW, Kaufman GA, Kaufman DW. 2005. Rodent seed predation and GUDs: effect of burning and topography. Canadian Journal of Zoology 83(10):1279-1285. DOI 10.1139/z05- 124.

Shepherd JD, Ditgen RS. 2013. Rodent handling of Araucaria araucana seeds. Austral Ecology 38(1):23-32. DOI 10.1111/j.1442-9993.2012.02366.x.

Steele MA, Contreras TA, Hadj-Chikh LZ, Agosta SJ, Smallwood PD, Tomlinson CN. 2014. Do scatter hoarders trade off increased predation risks for lower rates of cache pilferage? Behavioral Ecology 25(1):206-215. DOI 10.1093/beheco/art107.

Steele MA, Rompre G, Stratford JA, Zhang HM, Suchocki M, Marino S. 2015. Scatter-hoarding rodents favor higher predation risks for cache sites: the potential for predators to influence the seed dispersal process. Integrative zoology 10(3):257-266. DOI 10.1111/1749-4877.12134.

Tang YY, Xie YG, Yu GG, Wu CP, Liu CX, Bi N, Shen YX. 2011. Seasonal dynamics and strategies of soil seed banks in karst region of northwest Guizhou. Chinese Journal of Ecology 30(7): 1454-1460.

Vander-Wall SB. 2000. The influence of environmental conditions on cache recovery and cache pilferage by yellow pine chipmunks (Tamias amoenus) and deer mice (Peromyscus maniculatus). Behavioral ecology 11(5):544-549. DOI 10.1093/beheco/11.5.544.

Vander-Wall SB. 2003. Effects of seed size of wind-dispersed pines (Pinus) on secondary seed dispersal and the caching behavior of rodents. Oikos 100:25-34. DOI 10.1034/j.16 00-0706.2003.11973.x.

Wang B, Corlett RT. 2017. Scatter-hoarding rodents select different caching habitats for seeds with different traits. Ecosphere 8(4):e01774. DOI 10.1002/ecs2.1774.

Wang GH, Yang ZX, Chen P, Tan WN, Lu CH. 2019a. Seed Dispersal of an Endangered Kmeria septentrionalis by Frugivorous Birds in a Karst Habitat. Pakistan Journal of Zoology 51(3):1195-1198. DOI 10.17582/journal.pjz/2019.51.3.sc5.

Wang J, Kang M, Huang H. 2014. Long-distance pollen dispersal ensures genetic connectivity of the lowdensity tree species, Eurycorymbus cavaleriei, in a fragmented karst forest landscape. Conservation genetics 15(5): 1163-1172. DOI 10.1007/s10592-014-0608-x.

Wang J, Yan QL, Lu DL, Diao MM, Yan T, Sun YR, Yu LZ, Zhu JJ. 2019b. Effects of microhabitat on rodent-mediated seed dispersal in monocultures with thinning treatment. Agricultural and Forest 
$356 \quad$ Meteorology 275:91-99. DOI 10.1016/j.agrformet.2019.05.017.

357 Zhang HM, Yan C, Chang G, Zhang ZB. 2016. Seed trait-mediated selection by rodents affects mutualistic 358 interactions and seedling recruitment of co-occurring tree species. Oecologia 180(2):475-484. DOI $359 \quad 10.1007 / \mathrm{s} 00442-015-3490-4$.

Zhang ZH, Hu G, Zhu JD, Ni J. 2013. Aggregated spatial distributions of species in a subtropical karst forest, southwestern China. Journal of Plant Ecology 6(2):131-140. DOI 10.1093/jpe/rts027.

Zheng YF. 2016. Study on effective component and bioactivity of Kmeria septentrionalis. Guangxi University. 
Figure 1

Fig.1 Location map of Mulun National Nature Reserve, China.

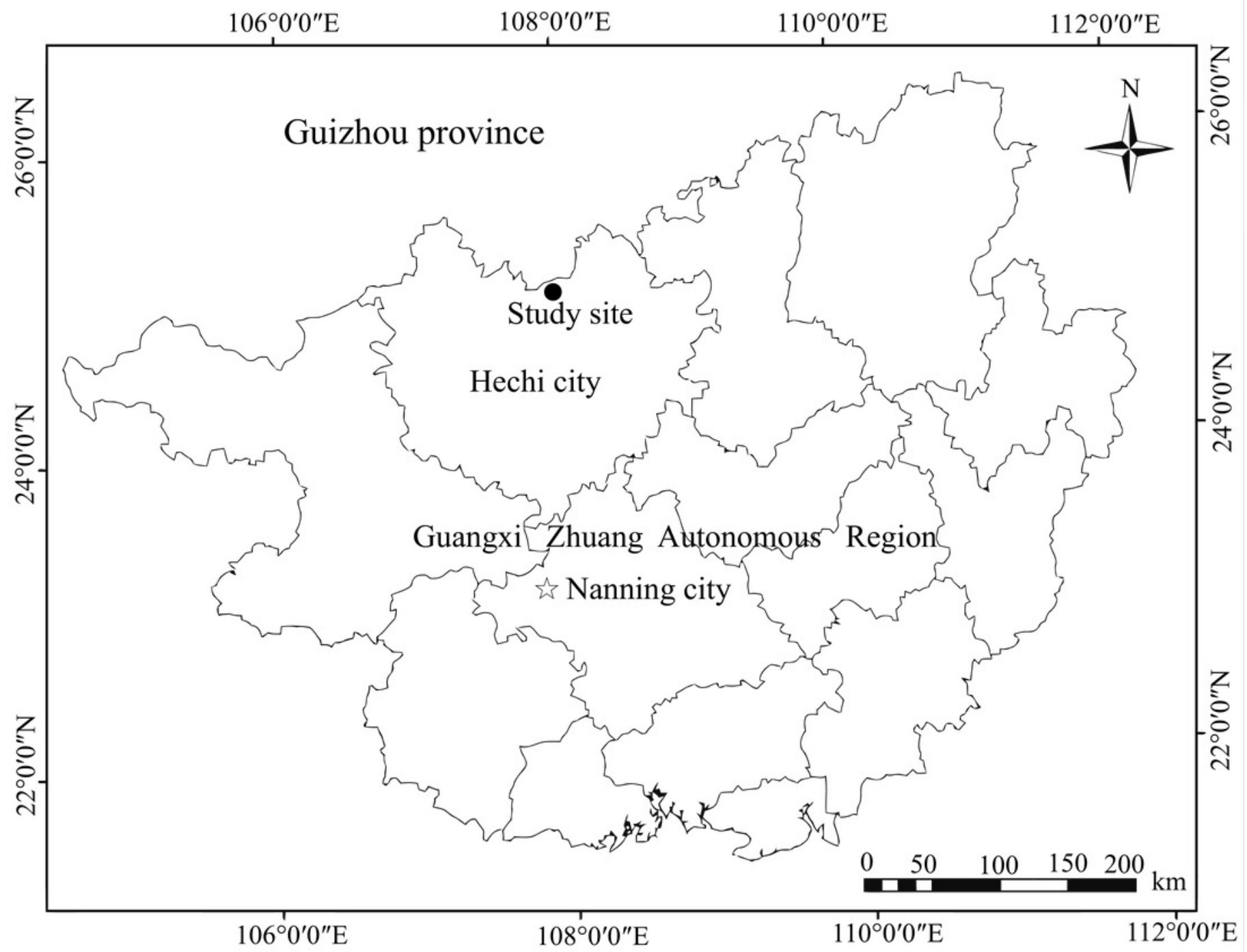


Figure 2

Fig. 2 Photograph of four karst microhabitats in the study area.
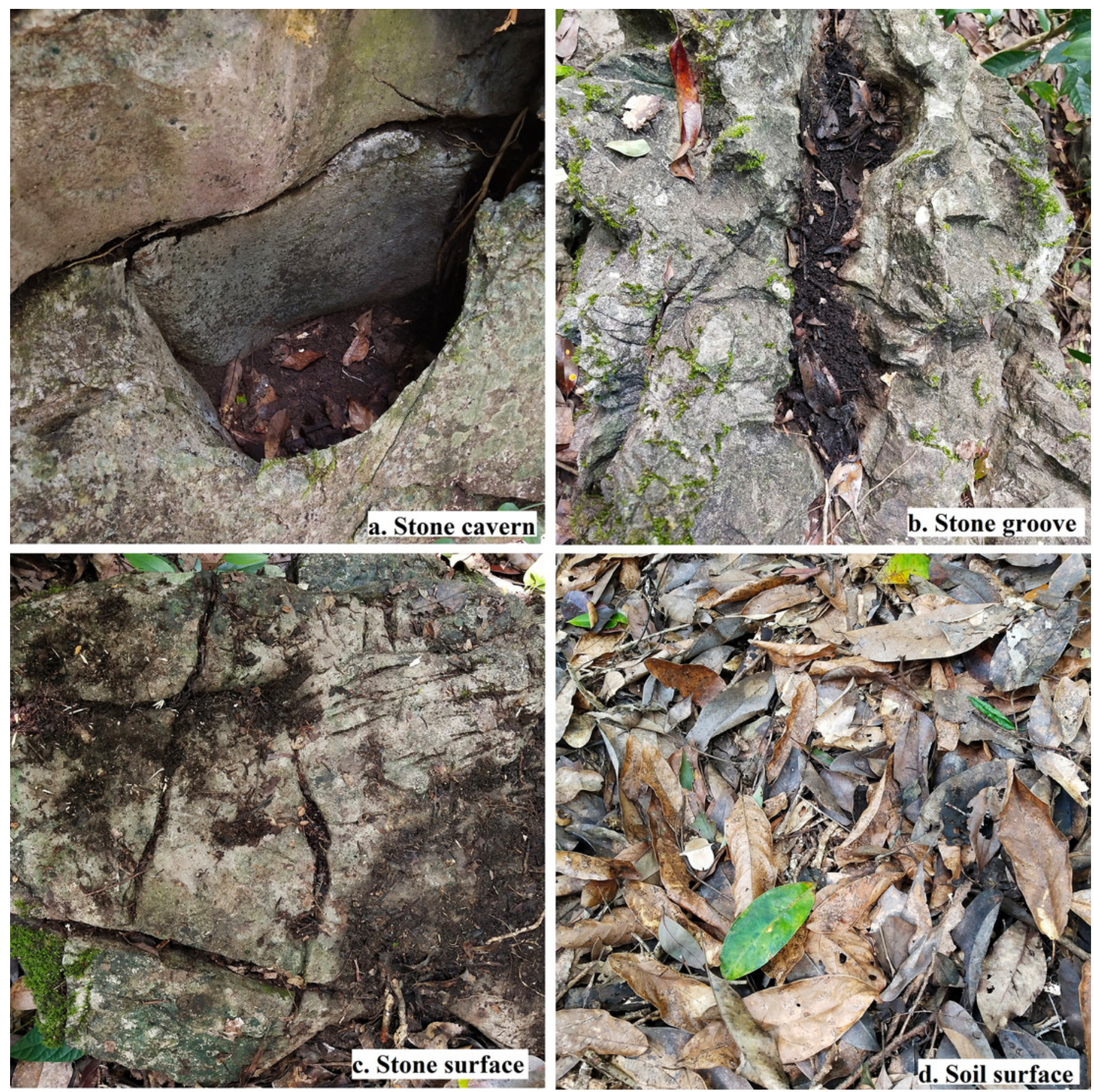
Figure 3

Fig. 3 The seed removal rates in different microhabitats and seed types.

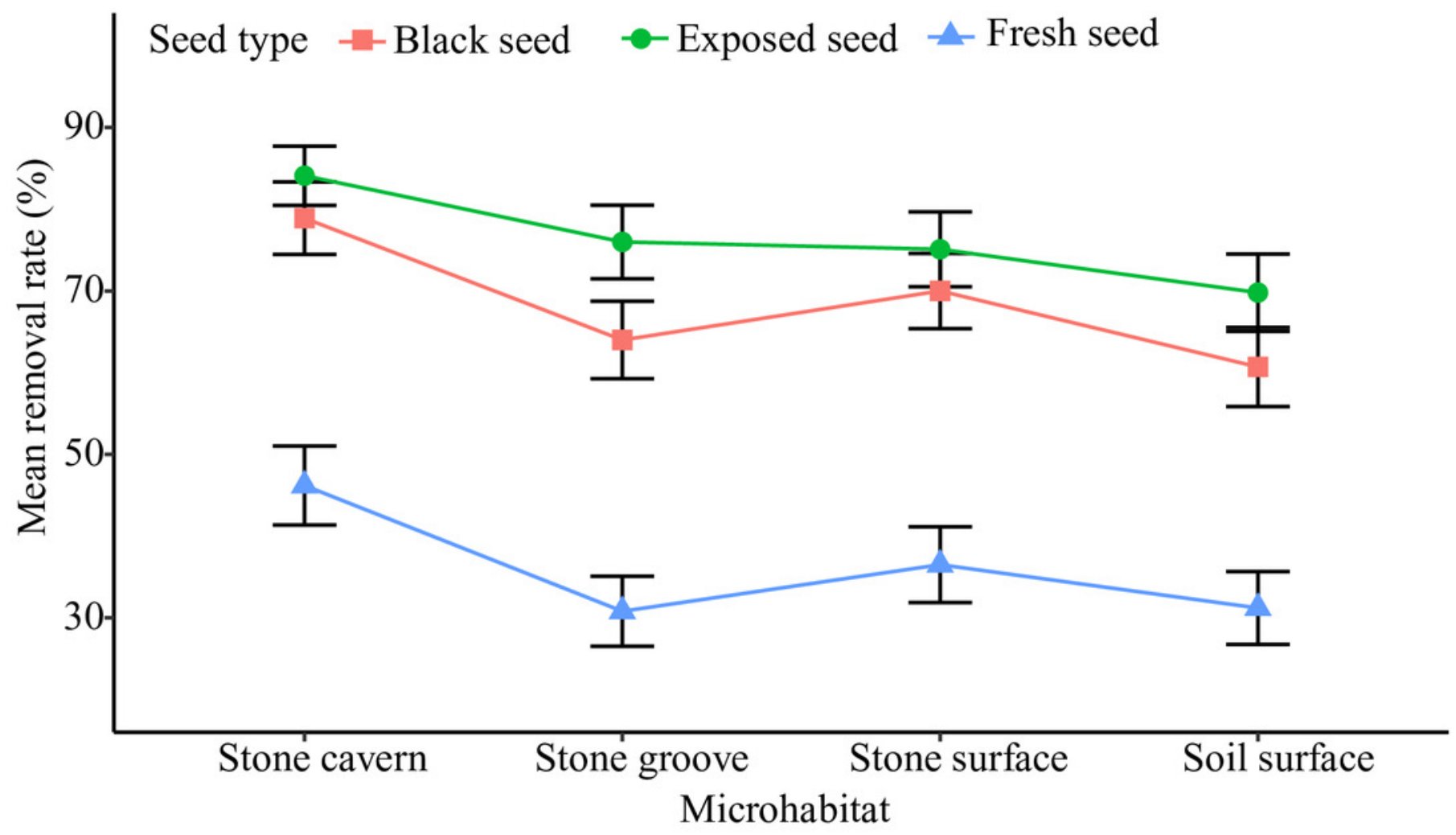




\section{Table $\mathbf{1}$ (on next page)}

Table1 Describe of karst microhabitats in the study area. 
Table1 Describe of karst microhabitats in the study area.

Microhabitat Describe

Stone cavern the bedrock vertical sunken to form a semi closed cave

Stone groove the bedrock protrudes horizontally to form a semi-closed strip-like fissure

Stone surface a small tableland with more than $30 \%$ of the bedrock exposed

Soil surface a continuous soil surface with a length and width greater than $2 \mathrm{~m}$

2 


\section{Table 2 (on next page)}

Table 2 Results of generalized linear mixed models (GLMM) evaluating the effects of microhabitats and seed types on the removal rate of $\mathrm{K}$. septentrionalis seeds. 
1 Table 2 Results of generalized linear mixed models (GLMM) evaluating the effects of microhabitats and seed 2 types on the rodent-mediated seed removal rate.

\begin{tabular}{lcccc}
\hline Variable & Estimate & Standard error & t-value & P-value \\
\hline Intercept & 0.456 & 0.059 & 7.799 & 0.000 \\
Microhabitat & -0.226 & 0.089 & -2.523 & 0.012 \\
Seed type & 0.871 & 0.113 & 7.686 & 0.000 \\
Microhabitat*Seed type & -0.019 & 0.275 & -0.068 & 0.946 \\
\hline
\end{tabular}

3 